\title{
Effects on applying micro-film case-based learning model in pediatrics education
}

\author{
Yuan Pan ${ }^{1,2}$, Xiuqi Chen ${ }^{3}$, Qiuwen Wei $^{3}$, Jinmin Zhao ${ }^{1 *}$ and Xun Chen ${ }^{3^{*}}$ (D)
}

\begin{abstract}
Background: In view of the harsh reality Chinese paediatricians face, the challenge of paediatric education is about instilling not only knowledge and clinical skills but also resilience and beliefs. The aim of the study is to explore a more effective method than the traditional lecture-based learning (LBL) model for optimizing educational outcomes by establishing an innovative, comprehensive, case-based learning (CBL) model combined with the micro-film technique (MF $+\mathrm{CBL})$. This approach has four important components: interests (attraction), knowledge application, competency, and scenario coping skills.

Methods: Experimental research was conducted via a controlled parallel group study. The total sample of 104 senior-year students (Chinese) majoring in clinical medicine was randomly divided into two groups. The experimental group was exposed to the MF + CBL model and the control group to the LBL model. Overall, the results were assessed after an 8-week course via a student self-assessment questionnaire, a satisfaction survey and the final examination.

Results: The experimental group generally performed better than the control group on the student self-assessment $(P<0.05)$, satisfaction survey $(P<0.05)$, and final examination $(80.02 \pm 3.77$ vs $73.65 \pm 3.69, P=0.000)$. The open question at the end of the questionnaire revealed that a small number of students did not favour the MF $+\mathrm{CBL}$ model due to its time- and energy-consuming features.
\end{abstract}

Conclusions: Compared with $L B L$, the MF + CBL model was an innovative teaching method that promoted more comprehensive quality development. It represents an alternative model for optimizing the capacity of future paediatric doctors.

Keywords: Case-based learning, Micro-film, Teaching method, Paediatrics

\section{Background}

The shortage of paediatricians in China is alarming. According to statistics published in Pediatrics in 2019, China has approximately 135 thousand paediatricians; these doctors face a severe service gap of 1 paediatrician per 2500 children (1:2500). The situation will worsen as

\footnotetext{
*Correspondence: zhaojinmin@126.com; chenxun1227@163.com 'Department of Graduate Administration, Guangxi Medical University, Nanning, 22 Shuangyong Road, Nanning, Guangxi, People's Republic of China

${ }^{3}$ Department of Pediatrics, the First Affiliated Hospital of Guangxi Medical University, 6 Shuangyong Road, Nanning, Guangxi, People's Republic of China

Full list of author information is available at the end of the article
}

the drop-out rate increases to approximately $12.6 \%$ [1]. Thus, paediatrics is trapped in an undesirable situation from the perspective of medical students.

Considering the harsh realities Chinese paediatricians face, such as lower salaries but heavier workloads, pressure deriving from the high expectations of patients' family members, and greater occupational risks for medical disputes than other specialists [2], paediatric education is facing the challenge of cultivating a competent workforce with knowledge, resilience and beliefs [3].

Paediatrics is a course that can offer a first impression of the profession to paediatric medical students, playing a crucial role in both training talent and changing the

C The Author(s). 2020 Open Access This article is licensed under a Creative Commons Attribution 4.0 International License, which permits use, sharing, adaptation, distribution and reproduction in any medium or format, as long as you give appropriate credit to the original author(s) and the source, provide a link to the Creative Commons licence, and indicate if changes were made. The images or other third party material in this article are included in the article's Creative Commons licence, unless indicated otherwise in a credit line to the material. If material is not included in the article's Creative Commons licence and your intended use is not permitted by statutory regulation or exceeds the permitted use, you will need to obtain permission directly from the copyright holder. To view a copy of this licence, visit http://creativecommons.org/licenses/by/4.0/ The Creative Commons Public Domain Dedication waiver (http://creativecommons.org/publicdomain/zero/1.0/) applies to the data made available in this article, unless otherwise stated in a credit line to the data. 
dire situation in children's health care services. Therefore, the mission of paediatrics is to attract talent, impart knowledge, develop competence and improve scenario coping to tackle the challenge posed by complex physical-psycho-social problems [4-6].

The rapid development of health care needs and the relative lag in comprehensive teaching modes have created higher requirements for the medical education system and greater challenges for medical educators. Previous studies have revealed the limitations of the traditional lecture-based learning (LBL) model with respect to problem-solving, collaborative learning, and lifelong learning strategies and have noted side effects such as decreased motivation and poor self-study, practical application and critical thinking abilities [7-9].

Contemporary medical education applies the problembased learning (PBL) model and case-based learning (CBL) model as innovative teaching strategies; these approaches, which feature small-group, case-based discussion [10], have been proven to be highly effective in improving student/faculty satisfaction, encouraging lifelong learning and curiosity, and improving clinical and critical thinking and problem-solving ability [11]. However, the CBL model surpasses the PBL model in target orientation and effective in-depth learning through advance preparation and guiding clarification [12].

Although the CBL model is proven to be helpful in promoting professional competence by creating opportunities to handle medical case situations [13] aimed at facilitating knowledge assimilation and strengthening critical thinking [14], scenario teaching filled with humanities [15] and social medicine elements is insufficient $[16,17]$. In addition, the number and diversity of cases is limited [18], which decreases students' learning interest [19].

An innovative model blending the micro-film technique with the CBL model $(\mathrm{MF}+\mathrm{CBL})$ may solve the above problems by establishing a sustainable learning mechanism including four important elements of education: interests (attraction), knowledge application [20], competency, and scenario coping skills. Blended microfilm teaching models have been widely used in humanities and social sciences teaching. As an artistic teaching form, micro-film can be helpful for case creation by folding social factors, such as interpersonal interaction and a sense of values, into scenarios. It leverages the expressive advantages of a film while being much shorter, entertaining and interactive [21]. The time-efficient production cycle and low cost ensure the feasibility of collecting typical case videos in daily clinical work. Moreover, case creation with video fragments protects infants and children from the risk of repeating direct exposure.

Like the CBL model, the MF + CBL model unfolds a case, through the storytelling technique [22], within a specific socio-cultural context, allowing medical students to see things in a different way by seeking meaning through the application of knowledge and deepening their understanding of the wisdom of the adage "to cure sometimes, to relieve often, to comfort always." Nevertheless, little research has been conducted on the application of the MF + CBL model in paediatrics teaching. Thus, this paper will demonstrate the effect of the MF + CBL model by comparing the traditional LBL model and innovative $\mathrm{MF}+\mathrm{CBL}$ model with respect to students' capacity development.

\section{Methods \\ Participants}

The study population comprised 104 undergraduates (Chinese) in their senior year studying clinical medicine at Guangxi Medical University, including 42 males and 62 females aged 25-27 years. The sample size was calculated by the sample size calculator [23]. By using the satisfaction degree in previous study [7] of the experimental group (92.5\%), and of control group (70\%), $\alpha=0.05$, powder $=80 \%$, Sampling Ratio $=1: 1$, the effective sample size needed was at least 44 students per group. All the participants including teachers and students were all signed the Informed Consent, which required keeping confidential about course materials. All the students were divided into two parallel groups (52 students per group) by random sampling with a random number generator. The group exposed to the MF + CBL model was named the experimental group, while the group exposed to the LBL model was named the control group. There was no significant difference between the two groups in gender $(P=0.842)$, age $(P=0.253)$ or academic record $(P=0.347)$ (Appendix 1).

\section{Design \\ General curriculum arrangement}

The textbook used was Pediatrics (Wang WP, 2018, People's Medical Publishing House, Ninth Edition), based on which the teachers developed PowerPoints as supplements. Pneumonia, asthma, hyaline membrane disease and meconium aspiration syndrome were the 4 chapters chosen for this study, highlighting pathogenesis, diagnosis and treatment. Each chapter was covered in 6 class hours over 2 weeks, for a total of 24 class hours over 8 weeks.

\section{Experimental group ( $M F+C B L$ model) design}

Based on the task-oriented model, the whole experimental group was divided into four sub-groups according to the four chosen chapters. Each sub-group was responsible for making a micro-film with the help of the teacher, who performed the advanced work of taping case videos of children's symptoms, such as pneumonia, 
fever, cough, wheezing, cyanosis and dyspnoea. The whole 8-week $\mathrm{MF}+\mathrm{CBL}$ process was divided into 2 periods.

Period 1 was characterized by teacher-oriented CBL focus group discussion [24], while period 2 featured student-oriented micro-film presentations, followed by expert comments and conclusions (Fig. 1). In period 1, the teacher served as a leader to explain the experimental curriculum and requirements, clarified key knowledge points, demonstrated clinical observation and reasoning in wards, and assisted groups with information analysis in the focus group discussion. With respect to the micro-film making, students were required to present a case story containing both clinical factors, such as pathogenesis, diagnosis, and treatment, and related social medicine factors, such as poverty and humanism, sexual discrimination, and doctor-patient relationships. Students were encouraged to discuss these factors in a focus group under CBL structured questioning guidelines provided by the teacher [25].

In Period 2, students played a central role in the micro-film presentation. The teachers shifted to serving as organizers, arranging the class discussions and expert comments. The experts invited included clinicians, doctor-patient relation coordinators, social health management professors, members of the media and film industry.
The photographic equipment consisted of the iPhone X, 2017, Apple Inc., and the video editing software was Videoleap Pro, 2017 Lightricks Ltd., downloaded from the App Store.

\section{Control group (LBL model) design}

The whole teaching process was divided into 4 periods corresponding to the chosen chapters, which were covered in teacher-centred lectures with the help of PowerPoints and the necessary pictures and videos typically used, but no media such as micro-films were used. The teacher's predominant role remained unchanged from beginning to end (Fig. 1).

Crucial potential confounding variables were controlled. In the 8-week teaching experiment, the experimental group $(\mathrm{MF}+\mathrm{CBL})$ and control group (LBL) used the same basic resources, including classroom sites and basic teaching materials (textbooks, PowerPoints, pictures, audio/video assistance, extra reading materials, etc.). In addition, all the teachers involved were at a similar level according to a comprehensive teaching evaluation and were trained in advance to avoid the introduction of subjective factors.

\section{Evaluation method}

To realize a comprehensive evaluation, both process assessment and outcome assessment were applied in this

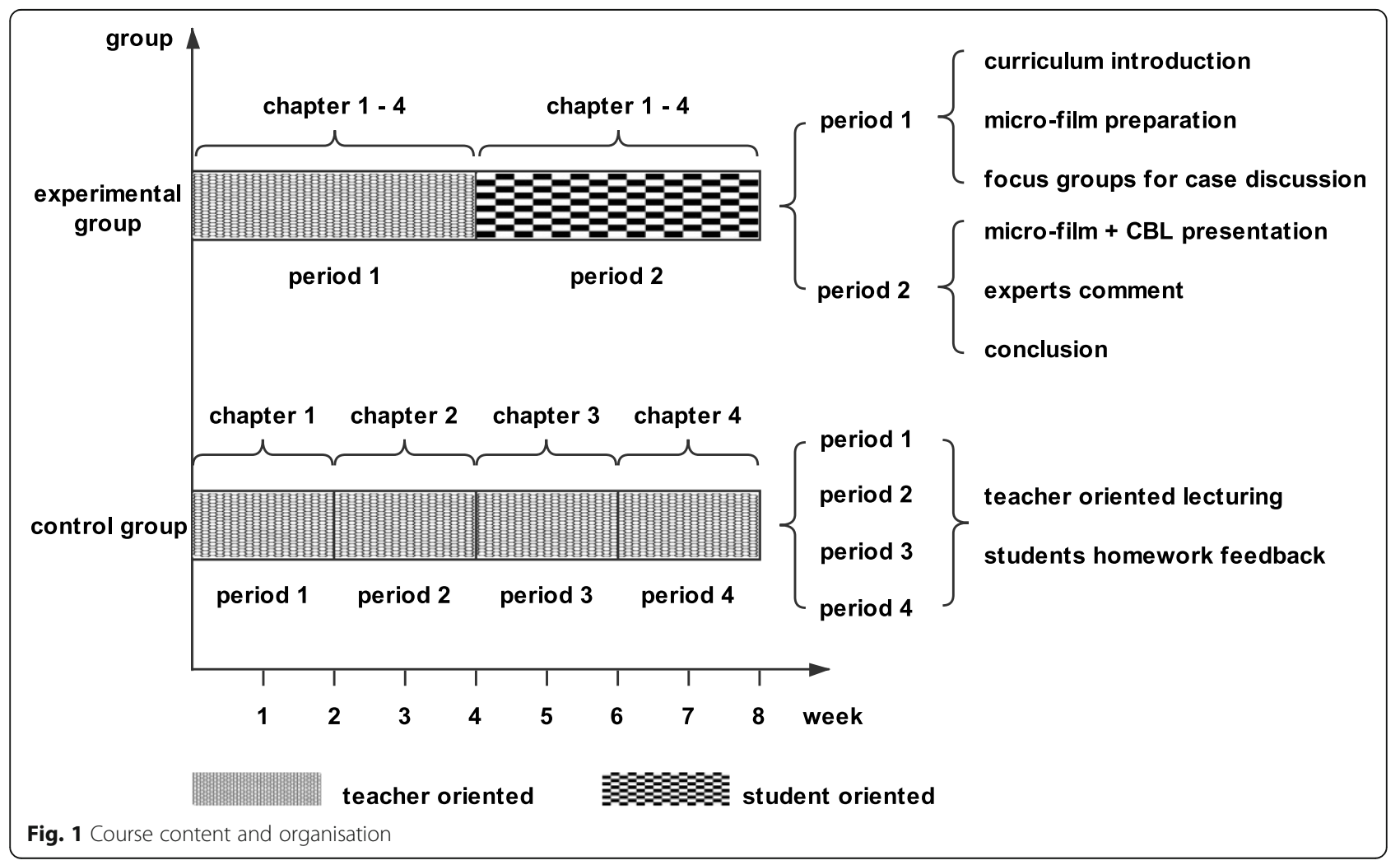


research. A student self-assessment questionnaire and a satisfaction survey were used for process assessment (Appendix 2); in addition, the final closed-book examination scores were used for outcome assessment.

The student self-assessment questionnaire subjectively evaluated knowledge application, competency, and scenario coping skills by exploring students' self-evaluation of their fundamental knowledge, clinical thinking, critical thinking, learning creativity, situation coping, and comprehensive capacity. The satisfaction survey mainly evaluated interests (attraction) by exploring students' opinions about the teaching materials, methods and selfefficacy [26]. The final closed-book examination objectively evaluated the students' command of fundamental knowledge and clinical comprehensive capacity by the last course of the 8-week experiment. In advance of the 8-week experiment, all the student participants were informed about the final closed-book examination, and there was no time for review. The final closed-book examination was designed and scored by all the teachers involved in the 8-week teaching experiment. The teachers signed confidentiality agreements, and the test papers were scored anonymously.

\section{Statistical analysis}

All statistical analyses were performed with SPSS software (version 24.0), including the validity and reliability tests of all the measures. The measurement data were expressed in the form of ${ }^{-} \mathrm{x} \pm \mathrm{s}$. Significance was assessed via an independent samples t-test. Categorical data were analysed by the chi-square test to compare teaching effects between the two groups. $P<0.05$ was considered statistically significant.

\section{Results}

The validity and reliability of the measures

The validity and reliability of the three measures were tested, and the following results were obtained in Appendix 3 .

\section{Comparison of the self-assessment results between the experimental group and the control group}

The results of the self-assessment questionnaire revealed that the experimental group surpassed the control group in terms of fundamental knowledge $(P=0.010)$, clinical thinking $(P=0.038)$, situation coping $(P=0.000)$, critical thinking $(\mathrm{P}=0.000)$, and learning creativity $(\mathrm{P}=0.000)$ (Table 1). The open question at the end of the questionnaire revealed that a small number of students did not favour the $\mathrm{MF}+\mathrm{CBL}$ model because it was more time consuming and energy consuming than self-study.
Table 1 Comparision of the self-assessment results between the experimental group and the control group

\begin{tabular}{|c|c|c|c|c|c|c|}
\hline \multirow{2}{*}{$\begin{array}{l}\text { Group } \\
\text { Self - assessment }\end{array}$} & \multicolumn{2}{|c|}{$\begin{array}{l}M F+C B L \\
(n=52)\end{array}$} & \multicolumn{2}{|c|}{$\begin{array}{l}\text { LBL } \\
(n=52)\end{array}$} & \multirow[t]{2}{*}{$x^{2}$} & \multirow[t]{2}{*}{$\mathbf{P}$} \\
\hline & Yes & No & Yes & No & & \\
\hline Fundamental knowledge & 40 & 12 & 29 & 23 & 4.306 & 0.038 \\
\hline Clinical thinking & 43 & 9 & 30 & 22 & 6.618 & 0.010 \\
\hline Situation coping & 50 & 2 & 18 & 34 & 40.827 & 0.000 \\
\hline Critical thinking & 46 & 6 & 20 & 32 & 25.917 & 0.000 \\
\hline Learning creativity & 40 & 12 & 18 & 34 & 17.190 & 0.000 \\
\hline
\end{tabular}

Yes: satisfaction, No: dissatisfaction, MF + CBL: Case-based learning model with micro-film technique. LBL: Lecture-based learning

Comparison of the final examination results between the experimental group and the control group

The final examination scores indicated that the experimental group had a higher aggregate score than the control group $(80.02 \pm 3.77$ vs $73.65 \pm 3.69, P=0.000)$ and especially outperformed the control group in terms of fundamental knowledge $(39.44 \pm 2.65$ vs $37.12 \pm 2.24$, $\mathrm{P}=0.000)$ and case study $(40.58 \pm 1.97$ vs $36.53 \pm 2.54$, $\mathrm{P}=0.000$ ) outcomes (Table 2 ).

\section{Comparison of the satisfaction survey results between the experimental group and the control group}

The results of the satisfaction survey demonstrated that the experimental group was more satisfied than the control group in terms of lecture content $(P=0.010)$, teaching method $(P=0.029)$ and student self-efficacy $(P=$ 0.025) (Table 3).

\section{Discussion}

To meet the ever-changing challenges faced by medical education, this research aimed to establish a sustainable learning mechanism integrating interests (attraction), knowledge application, competency, and scenario coping skills. During this immersive learning process, students were required to intensively engage in case observation, analytical discussion and summarization, guided by the teacher. The teaching quality depended on the functional roles of the teacher and student in a loop of mutual reinforcement and was evaluated by designed assessments administered individually to both students and teachers (Fig. 2). Thus, the effect of the advanced teaching mode blending CBL with the micro-film technique is discussed below based on the results of all the measures.

First, the MF + CBL model was more attractive to students than the LBL model, as indicated by the results of the satisfaction survey on the three dimensions of the course content, the teaching method and student selfefficacy. Since the course content was the control variable, the teaching method and the learning process, as well as students' feelings of enrichment, were more likely 
Table 2 Comparison of the final examination results between the experimental group and the control group (scores, ${ }^{-} x \pm s$ )

\begin{tabular}{|c|c|c|c|c|}
\hline Group & $\mathrm{MF}+\mathrm{CBL}(n=52)$ & LBL $(n=52)$ & $X^{\top}$ value & $P$ value \\
\hline Fundamental knowledge & $39.44 \pm 2.65$ & $37.12 \pm 2.24$ & 4.835 & 0.000 \\
\hline Case study & $40.58 \pm 1.97$ & $36.53 \pm 2.54$ & 9.054 & 0.000 \\
\hline Total score & $80.02 \pm 3.77$ & $73.65 \pm 3.69$ & 8.703 & 0.000 \\
\hline
\end{tabular}

MF + CBL: Case-based learning model with micro-film technique. LBL: Lecture-based learning

to influence the satisfaction level. The outcomes were probably due to the fact that, first, with the micro-film stories, the CBL model was updated to live-CBL or eCBL [27], which was more vivid than lines in a textbook; second, the micro-films were an aesthetic fruit produced through medical students' diligent interdisciplinary effort, and the presentation stimulated their inner potential with respect to teamwork, case reasoning and scaffolding for case presentations [28]; third, the CBL model, with its structured question technique, was more effective in guiding students to apply fundamental knowledge to practical clinic situations, narrowing the gap between knowledge and usage [29], which may have increased self-efficacy and thereby motivated learning initiative and creativity [30].

Second, MF + CBL model may be more effective than the LBL model with respect to knowledge application, which can be proved by the higher scores in terms of fundamental knowledge and case analysis in the experimental group (Table 2). The higher average score might reflect better capacity of memorizing, understanding and clinical comprehensive capacity. Since traditional LBL model was characterized by its teacher-centred efficiency in a cramming system, where students could only seize fragments of knowledge by rote [31], whereas the MF + CBL model increased students' automatic processing by providing abundant opportunities for experiential practice [32]. In addition, the micro-film told a case story based on the development of an illness, which followed the natural laws of medical practice and knowledge assimilation, as well as encouraged the study of cases in context, within which students could realize knowledge application through the mutual reinforcement of learning and practice. However, the KMO value (0.500) of the closed-book examination, make Cronbach's alpha (0.866) not fully reliable. The likely reasons may be the test paper contained only two parts, objective questions for fundamental knowledge and subjective questions for case analysis, which could not show a full picture of student's capability. In further research, we will used more mature test papers or other measurements to testify the result.

Third, the MF + CBL model more effectively developed students' learning capacity than the LBL model. Learning capacity can be evaluated by assessing critical thinking and learning creativity [31]. Requiring vast stores of knowledge, mastery of complex clinical situations and the incorporation of frontier learning, medical education not only focuses on the right answer but also on the right way through cultivating critical thinking based on a solid foundation of knowledge. Learning creativity can also help students persist in learning by motivating their thinking and inquiry. The reasons that the experimental group had higher "critical thinking" and "learning creativity" scores might be as follows: first, micro-film is a video expression technique that allowed information exploration. Students in the experimental group were encouraged to scan the available information for, for instance, important yet subtle clues, enhancing visual cue interpretation [32], or deviant behaviours obscured by dramatic plots, helping to trigger critical thinking. Second, the MF + CBL model was a creative learning method that could be assimilated by students as they improved their practical, medical humanities and evidencebased medicine competencies. Teaching did not end at the time of knowledge assimilation; instead, it continued in the construction of the student's learning model. Individuals established their learning model by acquisition [31] and further influenced others.

Fourth, the MF + CBL model better promoted students' situational understanding and coping than the LBL model. The social issues related to the patient or illness reflected in the MF + CBL model can expand students' case discussions to the bio-psycho-social system

Table 3 Comparison of the satisfaction survey results between the experimental group and the control group

\begin{tabular}{|c|c|c|c|c|c|c|c|c|}
\hline \multirow{2}{*}{$\begin{array}{l}\text { Group } \\
\text { Contents }\end{array}$} & \multicolumn{3}{|c|}{$\mathrm{MF}+\mathrm{CBL}(n=52)$} & \multicolumn{3}{|c|}{ LBL $(n=52)$} & \multirow{2}{*}{$\begin{array}{l}\mathrm{X}^{2} \\
\text { value }\end{array}$} & \multirow{2}{*}{$\begin{array}{l}P \\
\text { value }\end{array}$} \\
\hline & Yes & No & Degree & Yes & No & Degree & & \\
\hline Lecture content & 46 & 6 & $88.46 \%$ & 34 & 18 & $65.38 \%$ & 6.554 & 0.010 \\
\hline Teaching method & 43 & 9 & $82.69 \%$ & 32 & 20 & $61.54 \%$ & 4.782 & 0.029 \\
\hline Self - efficacy & 44 & 8 & $84.62 \%$ & 33 & 19 & $63.46 \%$ & 5.002 & 0.025 \\
\hline
\end{tabular}

Yes: satisfaction, No: dissatisfaction, Degree: degree of satisfaction, MF + CBL: Case-based learning model with micro-film technique. LBL: Lecture-based learning 


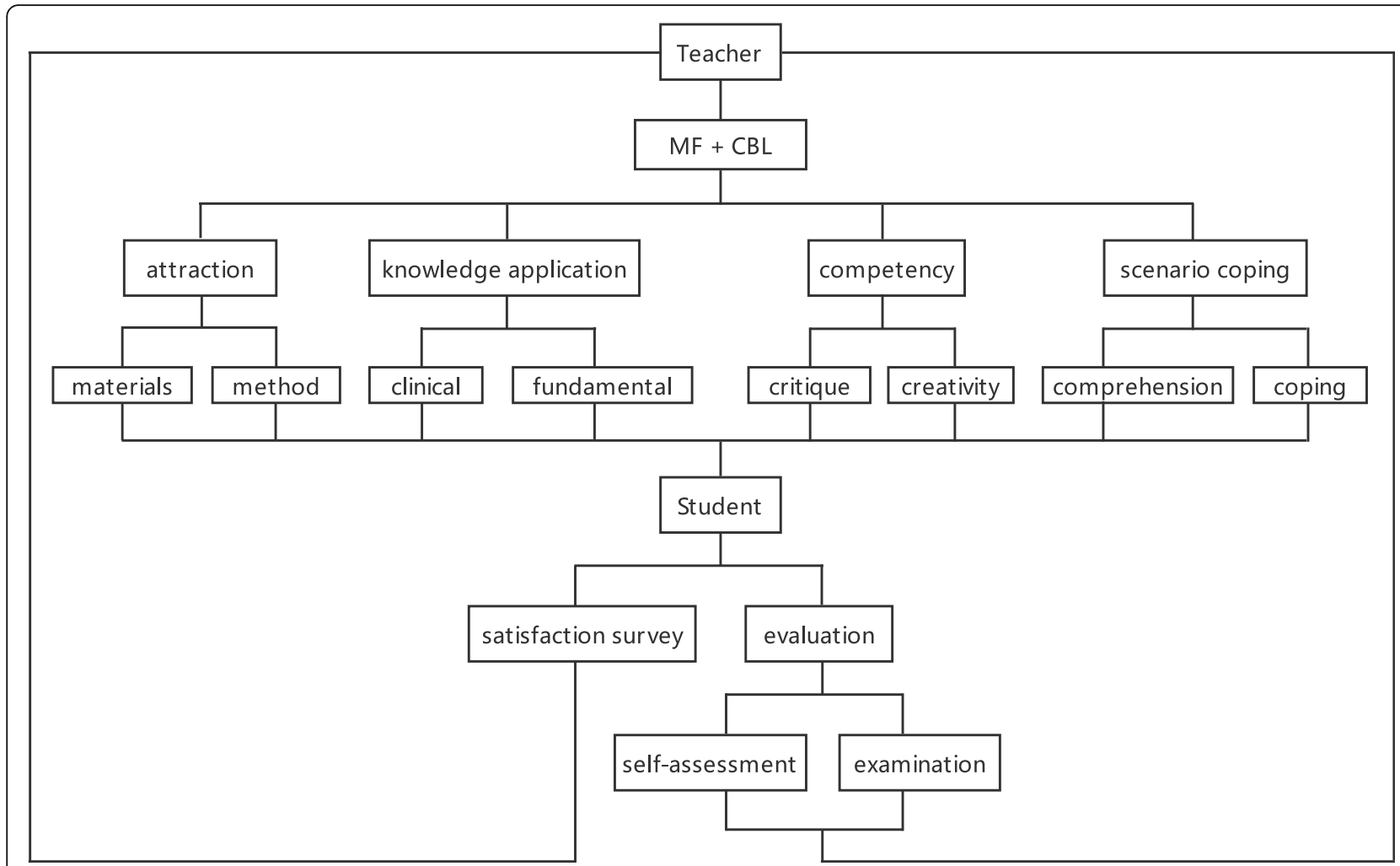

Fig. 2 Teaching effect and evaluation

of the patient [33]. Themes of social medical triggers, values affecting health service offerings, doctor-patient relationships, etc., can be revealed through structured guiding questions from the teacher in the $\mathrm{MF}+\mathrm{CBL}$ focus group. Such questions may include "How can we design a family rehabilitation plan for the patient?", "What are the risk factors for doctor-patient relationships in paediatrics? How can this relationship be improved?", and "In the medical field, how can children with special needs be helped in a sustainable way?". Thus, the learning procedure was also the gateway to practicing in scenarios [22]. Therefore, students were required to bring not only questions but also solutions to the case scenario. In addition, during the shooting process, students needed to interview hospital staff, patients and their families, and media staff, which deepened their comprehension of clinical practice and the dilemmas and social stress encountered in medical care, resulting in the improvement of their situational coping skills.

In reality, the $\mathrm{MF}+\mathrm{CBL}$ model had limitations as a demanding teaching method for both students and teachers in terms of students' willingness to engage in self-study, creative thinking, and expression and teachers' capacity to handle innovative techniques and group discussion leading and conclusion [34]. In addition, initial planning and extracurricular activities were important parts of the MF + CBL model, and some students-in the experimental group-expressed dissatisfaction with this innovative trial. We do not deny that cramming could lead to a better grade on an exam in the current Chinese education system, since the way the student obtains knowledge is not inherent but acquired based on the learning context or environmental influence. Nevertheless, the seemingly superior efficiency of imparting knowledge through lectures was outweighed by the disadvantages in terms of lack of critical thinking, which might limit students' capacity development to the path of mechanical memorization. The MF + CBL model was comparatively time-consuming if students sought to perform well but was useful in developing a deep approach to learning in students [31], which changed the target of learning from scores to strength.

\section{Limitations}

This study has several limitations. First, the teachers volunteered recruited in LBL or CBL group, the subjective influence from teachers could not be denied, though all the teachers involved in this study were appraised as above average prior to study implementation. Second, the study sample was recruited from within one institution, and the process took place over only 8 weeks covering 4 chapters, which might not be a broad enough or long enough scope to observe a stable change in medical 
students' educational outcomes. Third, the test paper design of closed book examination was imperfect reflected by the result of KMO value.

\section{Conclusions}

The results indicated that the MF + CBL model had greater efficacy than the traditional LBL model. The MF + CBL model was preferred and broadly beneficial to both teachers and students in the 8-week teaching experiment. The ever-changing demands of the health care system have pushed doctors to a higher level of capacity, requiring deeper thinking and critical analysis during unforeseen and unfamiliar situations or in research. It is timely to explore further how educators can improve and alter clinical teaching methods with the MF + CBL model to optimize students' learning effectively and to encourage a shift towards capacity building. Our findings call for long-term research covering the university educational and hospital clinical practice periods on the effect of curricular interventions on paediatrics to guide teaching innovation in medical education.

\section{Supplementary Information}

The online version contains supplementary material available at https://doi. org/10.1186/s12909-020-02421-w.

Additional file 1: Appendix 1. Demographic data.

Additional file 2: Appendix 2. Questionnaire for self-assessment and satisfaction survey.

Additional file 3: Appendix 3. Reliability and validity analysis results of three test methods.

Additional file 4: Appendix 4. GUANGXI MEDICAL UNIVERSITY ETHI CAL REVIEW COMMITTEE Approval Notice.

\section{Abbreviations}

CBL: Case-based learning; LBL: Lecture-based learning; MF + CBL: Case-based learning model with micro-film technique

\section{Acknowledgements}

The authors are grateful to the students and residents who dedicated their time to participate in the study.

\section{Authors' contributions}

YP, XC and JMZ were involved in the conception and design of the study. YP designed the framework and research methods under theoretical guidance of JMZ and the clinical guidance of XC. YP wrote the first draft of the paper. XQC and QWW were involved in experiment implementation. Al authors have read and approved the manuscript.

\section{Funding}

This study has been supported by the Innovation Project of Guangxi Graduate.

Education (JGY2020041 and YCBZ2020047).

\section{Availability of data and materials}

All data generated or analyzed during this study are included in this published article and its supplementary information files.

\section{Ethics approval and consent to participate}

This study was ethically approved by Guangxi Medical University's Ethics Committee (Appendix 4). In advance of the experimental research, all the participants including patients, teachers and students signed the informed consent.

\section{Consent for publication}

Not applicable.

\section{Competing interests}

The authors declare that they have no competing interests.

\section{Author details}

${ }^{1}$ Department of Graduate Administration, Guangxi Medical University, Nanning, 22 Shuangyong Road, Nanning, Guangxi, People's Republic of China. ${ }^{2}$ Department of Humanity and Social Sciences, Guangxi Medical University, Nanning, Guangxi, People's Republic of China. ${ }^{3}$ Department of Pediatrics, the First Affiliated Hospital of Guangxi Medical University, 6 Shuangyong Road, Nanning, Guangxi, People's Republic of China.

Received: 5 April 2020 Accepted: 3 December 2020

Published online: 09 December 2020

\section{References}

1. Zhang YJ, Huang LS, Zhou X, Zhang X, Zheng K, Wang ZX, Chen Q, Dong $X Y$, Du LJ, Fang JP, et al. Characteristics and workload of pediatricians. Pediatrics. 2019:144(1):e20183532.

2. Kesselheim J, Stockman L, Growdon A, Murray A, Shagrin B. Discharge Day: A Case-Based Interprofessional Exercise About Team Collaboration in Pediatrics. MedEdPORTAL. 2019;15:10830. https://doi.org/10.15766/mep_ 12374-18265.10830.

3. Hu Y, Xu J, Dong W, Yuan Z, Sun X. Strategies to correct the shortage of paediatricians in China. Lancet. 2018;392(10145):385.

4. Schwartz LR, Fernandez R, Kouyoumjian SR, Jones KA, Compton S. A randomized comparison trial of case-based learning versus human patient simulation in medical student education. Acad Emerg Med. 2007;14(2):1307.

5. Rea KE, Rao P, Hill E, Saylor KM, Cousino MK. Families' experiences with pediatric family-centered rounds: a systematic review. Pediatrics. 2018; 141(3):e20171883.

6. Jhala M, Mathur J. The association between deep learning approach and case based learning. BMC Med Educ. 2019;19(1):106-9.

7. Bi M, Zhao Z, Yang J, Wang Y. Comparison of case-based learning and traditional method in teaching postgraduate students of medical oncology. Med Teach. 2019:41(10):1124-8.

8. Ilkiw JE, Nelson RW, Watson JL, Conley AJ, Raybould HE, Chigerwe M, Boudreaux K. Curricular revision and reform: the process, what was important, and lessons learned. J Vet Med Educ. 2017;44(3):480-9.

9. Dickinson BL, Lackey W, Sheakley M, Miller L, Jevert S, Shattuck B. Involving a real patient in the design and implementation of case-based learning to engage learners. Adv Physiol Educ. 2018:42(1):118-22.

10. Roberts C, Lawson M, Newble D, Self A, Chan P. The introduction of large class problem-based learning into an undergraduate medical curriculum: an evaluation. Med Teach. 2005;27(6):527-33.

11. Srinivasan M, Wilkes $M$, Stevenson $F$, Nguyen $T$, Slavin S. Comparing problem-based learning with case-based learning: effects of a major curricular shift at two institutions. Acad Med. 2007;82(1):74-82.

12. McLean SF. Case-based learning and its application in medical and healthcare fields: a review of worldwide literature. J Med Educ Curric Dev. 2016;3: 39-49.

13. Weidenbusch M, Lenzer B, Sailer M, Strobel C, Kunisch R, Kiesewetter J, Fischer MR, Zottmann JM. Can clinical case discussions foster clinical reasoning skills in undergraduate medical education? A randomised controlled trial. BMJ Open. 2019:9(9):e025973.

14. Gartmeier M, Pfurtscheller T, Hapfelmeier A, Grünewald M, Häusler J, Seidel T, Berberat PO. Teacher questions and student responses in case-based learning: outcomes of a video study in medical education. BMC Med Educ. 2019;(1):455. https://doi.org/10.1186/s12909-12019-11895-12901.

15. Marcus ER. Empathy, humanism, and the professionalization process of medical. Acad Med. 1999;74(11):1211-5

16. Qu FW, He J, Ma H, Jiang YL, Zhao WL, Virasakdi C, Jiang RS. A comparative analysis of medical education models and curriculums of a Medical University and a medical education center. J Nepal Med Assoc. 2019; 57(215):45-9. 
17. Rosenstock J, Sparks GM. Training physicians for the real world of medicine: administration-based learning. Med Educ. 2016;50(12):1189-91.

18. Khin-Htun S, Kushairi A. Twelve tips for developing clinical reasoning skills in the pre-clinical and clinical stages of medical school. Med Teach. 2019:41(9): 1007-11.

19. Chandrasekar H, Gesundheit N, Nevins AB, Pompei P, Bruce J, Merrell SB. Promoting student case creation to enhance instruction of clinical reasoning skills: a pilot feasibility study. Adv Med Educ Pract. 2018;9:249-57.

20. Peñuela-Epalza M, De la Hoz K. Incorporation and evaluation of serial concept maps for vertical integration and clinical reasoning in case-based learning tutorials: perspectives of students beginning clinical medicine. Med Teach. 2018;41(4):433-40

21. Xiao-Jing Y. A study on the teaching marerials and methods of micro film courses in general university. Int J Organizational Innovation. 2017;9(3):15-8.

22. Yu H, Chang YT. How to influence the brand attitude of the audience by micro-films. J Promot Manag. 2013;19(5):674-86.

23. Sample size calculator. Available at: http://powerandsamplesize.com/ Calculators/Compare-2-Proportions/2-Sample-Equality. Accessed 01 Jun 2020.

24. Suliman S, Al-Mohammed A, Al Mohanadi D, Karim H, Elbuzidi A, Mubasher M, Rahil A. It is all about patients' stories: case-based learning in residents' education. Qatar Med J. 2019:3:17. https://doi.org/10.5339/amj.2019.5317.

25. Hassoulas A, Forty E, Hoskins M, Walters J, Riley S. A case-based medical curriculum for the 21st century: the use of innovative approaches in designing and developing a case on mental health. Med Teach. 2017;39(5): $505-11$

26. Colthart I, Bagnall G, Evans A, Allbutt H, Haig A, Illing J, McKinstry B. The effectiveness of self-assessment on the identification of learner needs, learner activity, and impact on clinical practice: BEME guide no. 10. Med Teach. 2008;30(2):124-45.

27. Turk B, Ertl S, Wong G, Wadowski PP, Löffler-Stastka H. Does case-based blended-learning expedite the transfer of declarative knowledge to procedural knowledge in practice. BMC Med Educ. 2019;19(1):447-56.

28. Braun LT, Zottmann JM, Adolf C, Lottspeich C, Then C, Wirth S, Fischer MR Schmidmaier R. Representation scaffolds improve diagnostic efficiency in medical students. Med Educ. 2017;51(11):1118-26.

29. Muthukrishnan SP, Chandran DS, Afreen N, Bir M, Dastidar SG, Jayappa H, Mattoo B, Navneet A, Poorasamy J, Roy A, et al. Planning, implementation, and evaluation of multicomponent, case-based learning for first-year Indian medical undergraduates. Adv Physiol Educ. 2019;43(4):504-11.

30. Thistlethwaite JE, Davies D, Ekeocha S, Kidd JM, MacDougall C, Matthews P, Purkis J, Clay D. The effectiveness of case-based learning in health professional education. A BEME systematic review: BEME guide no. 23. Med Teach. 2012;34(6):e421-44.

31. Chonkar SP, Ha TC, Chu SSH, Ng AX, Lim MLS, Ee TX, Ng MJ, Tan KH. The predominant learning approaches of medical students. BMC Med Educ. 2018;18(1):17-24

32. Cope AC, Bezemer J, Kneebone R, Lingard L. 'You see?' teaching and learning how to interpret visual cues during surgery. Med Educ. 2015;49(11): 1103-16.

33. Whitehead C, Selleger V, van de Kreeke J, Hodges B. The 'missing person' in roles-based competency models: a historical, cross-national, contrastive case study. Med Educ. 2014;48(8):785-95.

34. Allchin D. Problem- and case-based learning in science: an introduction to distinctions, values, and outcomes. CBE Life Sci Educ. 2013:12(3):364-72.

\section{Publisher's Note}

Springer Nature remains neutral with regard to jurisdictional claims in published maps and institutional affiliations.

Ready to submit your research? Choose BMC and benefit from:

- fast, convenient online submission

- thorough peer review by experienced researchers in your field

- rapid publication on acceptance

- support for research data, including large and complex data types

- gold Open Access which fosters wider collaboration and increased citations

- maximum visibility for your research: over $100 \mathrm{M}$ website views per year

At $\mathrm{BMC}$, research is always in progress.

Learn more biomedcentral.com/submissions 